\title{
An Investigation on Information Communication Technology Awareness and Use in Improving Livestock Farming in Southern District, Botswana
}

\author{
Clifford Matsoga Lekopanye \\ Final Year Student, MSc in Computing, \\ Teesside University, UK \\ (Botho University-Campus), Gaborone
}

\author{
Dr. Meenakshi Sundaram K \\ Faculty of Computing \\ Botho University \\ Gaborone, Botswana
}

\begin{abstract}
This paper investigated the extent of Information Communication Technology (ICT) usage by livestock keepers and limitations encountered. The study was conducted with the objective of coming up with findings that will contribute towards strengthening ICT usage for the development of livestock keeping. In order to meet this objective the researcher used a mixed method approach where by qualitative and quantitative methods were both used. The results of this study, showed mobile phone technology as the most popular ICT used by $89 \%$ of the respondents. Also $73 \%$ of the respondents indicated that they have access to the local radio channel, television accounted for $59 \%$. Other types of ICTs that were pointed out by few respondents are Facebook, Email, the Internet and YouTube. Livestock keepers have identified a number of limitations in using ICTs that need to be addressed that include high cost of communication, poor mobile communication signal, unawareness of television and radio program schedule, and lack of electricity in rural areas.

In conclusion, this study has identified ICTs such as radio, mobile phones, and television as types of ICT that are used most frequently by livestock keepers, though they are not used at satisfactory level for livestock production. Therefore, the researcher proposed that information systems aimed at delivering information to livestock keepers should be more mobile driven than being computer based. A major approach that could be adopted to address the challenges of radio and television usage is to come up with livestock programs that combine mobile technology with radio and television programs. Participants and listeners to radio or television programs could use mobile technologies to send in their questions either by calls or short messages.
\end{abstract}

Keywords-ICT; Livestock production; ICT utilization; information access; developing countries; ICT awareness

\section{INTRODUCTION}

Agriculture is a substantial activity in Botswana. The statistics show that $70 \%$ of the population is in rural areas and are actively involved in Agricultural activities [1]. Rural resident's living depends on Agriculture as a source of food, employment, and income. Botswana is a country that generally receives low and unreliable rainfall, regular outbreaks of cattle diseases such as Foot and Mouth Disease (FMD), and recurring droughts.

Popular livestock kept in Botswana are cattle, goats, sheep, donkeys, and poultry. The cattle population in Botswana is 3.6

The author would like to thank botho University (Gaborone Campus) for the support and sponsorship of this research work, for publication. million. Of these, $15 \%$ is under the commercial farming system, and the remaining $85 \%$ falls under the non-commercial farming system of small farms [1]. There are two categories of livestock farming systems in Botswana: firstly, the cattle posts, where individual farmers keep small herds of cattle; and secondly the livestock farming that is based on large herds of cattle managed under the communal grazing system [2].

The agriculture sector was contributing about $40 \%$ to Botswana's Gross Domestic Product (GDP) at independence, mainly through the beef exports [3]. The rate has dropped drastically over the years, recording a contribution of 2.6 percent to GDP in 2013. The production was mainly disadvantaged by traditional farming methods, recurring droughts, poor rainfall, and regular outbreaks of pests and diseases [4].

Information Communication Technology (ICT) is an umbrella name that includes any communication device such as computers, telephones, televisions, radio and others. There are also services and software that operates with the aforementioned devices such as email services, livestock management software tools, distance learning software tools and video conferencing applications among others

According to Williams [5], ICT is very important in improving livestock farming. ICT provides livestock farmers with latest livestock farming technology and disseminate formation [5, 6]. Previous researches have shown that ICT is a major contributing factor for improving livestock farming [7]. Local communities or farmers need to take part in decision making during the design and introduction of new ICT systems. Participation of livestock keepers is found to be the most effective way for successful ICT usage in livestock farming $[8,5]$.

It can be concluded that the use of ICT for record keeping, accessing and disseminating livestock information is an important aspect in increasing profitability. In order for the livestock sector to be economically efficient, livestock keepers need to properly manage all components of the livestock farming $[8,9]$.

This study will be conducted in order to empirically investigate the ICT awareness and usage by livestock farmers in Sothern district of Botswana with the aim to discover challenges that livestock keepers encounter in ICT usage in 
their livestock farming activities. It is anticipated that the research findings and suggested recommendations of this study will improve livestock information access and dissemination in the study area.

\section{RESEARCH PROBLEM}

The problem is, livestock farming productivity have being decreasing in Botswana over the past 50 years. Agriculture sector contributed about $40 \%$ to GDP in 1966 mainly through the beef exports [3]. The rate has dropped drastically over the years, to 2.6 percent in 2013, (Honde, 2015). This is a problem because it affects more than half of the population of Botswana. About $70 \%$ of the population make their living from farming [1]. Livestock farming is a source of income, source of food and provides employment opportunities for more than half of the population of Botswana. Hence the need to address this problem for improvement of the livelihood of livestock keepers.

There are challenges faced by livestock farmers with regards to livestock information access and dissemination. Lack of ICT infrastructure in rural areas and high cost of ICT services drive livestock keepers to use unproductive traditional ways of farming. They depend on traditional media like television, newspapers and radio as source of information. These traditional mass media cannot provide the services of record keeping nor detect a possible outbreak of diseases, and cannot meet the specific needs of individual livestock keepers. One other challenge faced by most livestock farmers is the language barrier. Most farmers only know their local languages while ICT applications are programed to run in English language. These challenges deprive livestock keepers the benefits that ICT could provide. Effective use of ICT will boost livestock sales and hence improve their livelihood.

According to available literature, no study has been done to determine awareness and usage of ICT for development on livelihoods of livestock keepers in Botswana. It remains unclear whether these ICT challenges apply in Botswana. Hence this study will be conducted in order to empirically investigate the ICT awareness and usage by livestock farmers in southern district of Botswana.

\section{PURPOSE OF THE STUDY}

Most of the livestock farmers are elders and their farming methods depend on traditional knowledge or local knowledge. Information knowledge, management, and communication plays an important role in development of livestock farming. With absence of ICT intervention or ICT usage farmers may remain using their old unproductive traditional knowledge of livestock farming. This study will be carried out in order to suggest ways that can improve livestock information access and dissemination.

According to available literature, no study has been done to determine awareness and usage of ICT for development on livelihoods of livestock keepers in Botswana. A comprehensive understanding of the relationship between ICTs and livestock keeping is still lacking in Botswana. Therefore this research is expected to bring about knowledge and awareness of the challenges encountered on usage of ICTs by livestock keepers. Challenges that apply in other countries may not apply in
Botswana. It is therefore, anticipated that this study will add new knowledge in ICT and livestock farming in Botswana. This study is conducted with the purpose of coming up with findings that will contribute towards strengthening ICT usage in livestock keeping. This study will be carried out to determine the level of ICT awareness and usage by livestock keepers. The study is meant to highlight the gap that exists on the ICT development in livestock sector in Botswana. The question is: Do livestock keepers in Botswana use ICT? If the answer is 'yes', then, to what extend are they using it? If the answer is 'no', then, what are the limiting factors? Therefore the study is designed to seek for answers to these questions.

\section{RESEARCH OBJECTIVES}

To find the level of ICT awareness and ICT usage by livestock Keepers in southern district of Botswana with the aim to discover challenges that livestock keepers are facing in using ICTs in livestock farming, in order to suggest ways of improving their ICT usage in their livestock farming activities.

\section{A. Specific Objectives}

1) To identify types of ICTs that livestock keepers use in the study area.

2) To examine the usefulness of ICTs used on accessing and disseminating livestock information.

3) To determine the economic status of livestock farmers in relation to the use of ICT.

4) To identify challenges encountered by livestock keepers in using ICTs in order to suggest ways of improving information access and dissemination.

\section{RESEARCH QUESTIONS}

\section{A. Main question}

To what extent are livestock keepers aware and use ICT in the study area?

\section{B. Specific questions}

1) From the existing types of ICTs, which ones are known and used by livestock keepers in the study area?

2) Are livestock keepers aware of theimportanceof ICT usage as information sharing tool in their livestock production business?

3) How does the economic status of livestock keepers relate with their ICT usage?

4) What limitations do livestock keepers encounter in using ICT?

\section{LITERATURE REVIEW}

This study investigates ICT awareness and usage for livestock farming development in the southern rural community of Botswana. The basis for conducting the study is to investigate on the limitations or challenges met by livestock keepers in accessing and using ICTs in rural communities. These limitations have negative effect in their productivity and the volume of their livestock production. The fundamental argument of the study is that employment of ICTs on livestock keeping has positive results of improving the quality and quantity of livestock production. In addition lack of ICT 
awareness can result in underutilization of available ICTs that could have enhanced livestock productivity.

\section{A. Types of ICTs that are known and used by livestock keepers in the study area}

The role of ICT in livestock farming is defined or determined by farmers, i.e. their ability to adopt and effectively use ICT in livestock farming activities. Use of ICT enables easy access and exchange of information which in turn increase efficiency, competitiveness and productivity in various livestock farming activities [7].

According to Angello [6] large scale commercial livestock keepers are expected to use digital imaging, cameras, computing devices, the internet, Wi-Fi, and Wireless Access Protocol (WAP) based Internet access among others, while small scale farmers utilize basic types of ICT such as computers, Internet and mobile phones.

Of all technologies, mobile phones are certainly the technology of choice for many livestock keepers in both large and small scale livestock production [7],[10], [11]. Mobile phones are cheap, easy to manage power efficient and have internet access that enable farmers to compare prices more efficiently and helps to improve the links between farmers and the market, creating more chances for small scale farmers to make more sales and hence improve their livelihoods.

The study that was conducted in Tanzania by [10] indicated that mobile phones were used most frequently by livestock keepers in getting information concerning their business. Other types of ICT such as radio and television are also used by a significant number of Tanzania livestock keepers. The Internet is accessed and used by quiet a small number of livestock keepers. Other studies that were conducted by [11], [7] showed similar results of high use of mobile phones, followed by television and radio with a minimum use of Internet, computers and email by livestock keepers.

\section{B. Awareness of the importance of ICT usage by livestock keepers}

The study that was done by [10], discovered that livestock keepers were aware of the importance of ICT usage.Furthermore, they indicated the need for information dissemination in order for their livestock keeping activity to grow and benefit them become more profitable. The study showed that $80 \%$ of the livestock keepers complained about lack of training personnel and also there is no time to conduct trainings. Livestock keepers suggested the use of television and radio to inform and educate livestock keepers since they have a wide coverage. According to Temba [10] livestock keepers requested that the broadcasting media should disseminate information on livestock diseases and control. From this, one can conclude that livestock keepers see the importance of ICTs such as radio and television. Therefore it is left for the broadcasting media to develop educative and informative programs on livestock keeping.

From the study that was conducted by [6], all the respondents that were part of the study did not have websites. Participants were not aware of websites, and a few reported to be using emails and livestock management applications. It is not surprising to get this kind of results more so that most livestock keepers are not computer literate. Livestock keeping applications and websites are more advanced information technology as compared to simple and cheap mobile phone technology that is mainly used for making calls and short messages.

\section{The economic status of livestock keepers in relation to their ICT usage}

One thing that can be used to measure how ICT usage relates with the socio-economic status of livestock keepers is the usage rate and diffusion rate of mobile phones. In Botswana the use or dispersal of mobile phones grew exponentially from 3301 in 1998 to 3,460,331 2016 [13]. One of the reasons for this is the low cost of mobile phones. The cost of a low specification mobile phone is about BWP 200.00 (US\$ 18.94). This shows that livestock keepers in Botswana are ready to adopt ICT when affordable. The text message service is the most popular service which clearly shows that most people can use related ICT services such as emails if they have access and can afford it.

For farmers to rip the benefits of ICT, first there should be ICT resources in place such as the computer hardware, computer software and internet access. However, the study that was conducted by [12] showed that most of livestock keepers in Botswana cannot afford to have ICT resources and internet access due to high costs. The cost of a minimum requirements specification computer is about BWP 3, 500.00 (US\$ 331.53) and internet connection charge is about BWP 500.00 (US\$ 47.36)

\section{Challenges that livestock keepers encounter in using ICT}

According to Arshad [14] livestock keeping can be improved through educating or training livestock keepers in their particular field. It is not easy and is expensive to conduct such trainings due to poor roads and dispersed livestock keepers. ICTs such as video conferencing, television and radio broadcasting could be used to educate livestock keepers at their particular field. However, these ICTs come with their challenges such as high cost of ICTs, lack of skills to use or operate them [14] and others that are discussed below.

\section{1) High cost of ICT and Electricity connection}

According to Mooketsi[15] few livestock keepers in Botswana use Internet in order to access online services due to lack of ICT infrastructure and electricity connection in rural areas. However, the author has observed that Batswana livestock keepers meet their goals when they work in collaborations. Livestock keepers in a certain area will come together and form syndicate in order to share the costs of drilling boreholes [15]. From this the author suggested that livestock keepers could possibly use the same idea to form groups in order to share costs of buying computers, connecting electricity to their homes or farms, and paying for the Internet cost. Therefore, livestock keepers are encouraged to take such initiatives and enhance their ICT usage in livestock keeping.

\section{2) Poor ICT infrastructure in rural areas}

The government of Botswana has been doing some developments over the past ten years in providing relevant ICT infrastructure. A lot of financial resources have been spent in 
ICT infrastructure. For the period of 2003 to 2010 the government invested $3.7 \%$ of national budget [16]. However, most of these ICT developments were implemented in government institutions such as secondary schools. Other ICT infrastructure challenges such as poor or limited radio and television signal coverage, Internet and power connection are not addressed, especially in rural communities.

\section{3) ICT Initiatives that are web-based}

Existing literature discuss some of the initiatives that employ the use of web-based ICTs in livestock keeping. This includes the VERCON in Egypt that use the Internet to establish and strengthen linkages among the livestock keepers, extension officers and agricultural researchers [17]. The VERCON connects geographically separate people with an enhanced two-way communication mode. Another initiatives that [18] has written a report about is the Linking Local Learners (LLL) in Kenya. This is a virtual network that connects livestock keepers' syndicates' together. In Uganda they have set up the District Agricultural Training and Information Centres (DATICS). In South Africa, a centralized Integrated Registration and Generic Information System (INTERGIS).

This projects or initiatives that are to fill the ICT gap in the livestock sector,however most of them are web-based. This makes it difficult for illiterate farmers to access and disseminate livestock information. Also, web-based solution brings about another challenge of poor Internet infrastructure and where it is available; it turns to be very expensive. Since, these initiative solutions are very useful, what can be done is to come up with easy ways for livestock keepers to navigate through, even those with low level education. The use of mobile phones is encouraged as they offer easy accessibility and are cheap to obtain. Although the use of short messages is cheap and requires basic level of literacy, it carries only a limited amount of information.

\section{METHODOLOGY}

\section{A. The research area}

This research study was conducted in the Ngwaketse Region, located in southern District part of Botswana. The Region lies between latitudes $-25^{\circ}$ South of the Equator and between longitudes $25^{\circ}$ East of Greenwich. The Ngwaketse region comprises of five (5) sub-regions, namely Barolong, Ngwaketse North, Ngwaketse South, Ngwaketse Central, and Ngwaketse East regions. This districts was selected purposively because of its bigger size, it has a high number of livestock holdings of 13, 202. According to CSO annual agricultural report, Sothern District has a total of 263, 974 cattle. The region is the second largest area to host beef farmers. There are several beef ranges that are run by the government. Also, there are privately owned large ranges that support livestock keepers in the area[1].

\section{B. Research design, sample size and sampling techniques}

In order to get answers of the research questions, the researcher adopted a mixed method approach. This means that quantitative and qualitative methods were both used. The researcher used observations and interviews for collecting qualitative data. The qualitative data was use to confirm the results from the collected quantitative data. Questionnaires were used to collect quantitative data so that the findings could be quantified in terms of percentages and frequencies. According to Creswell [19] it is advisable to use a mixed method approach because one of the used method will neutralize the shortfalls of the other used method.

In this study, both purposive method and snowball sampling techniques of non-probability were used in selecting the study sample. A combination of two non-probabilities. The purposive or judgmental method was used by the researcher to identify respondents that were most likely to answer the questionnaire and interview questions in a way that will lead to attaining the objectives of the study. Ministry of Agriculture have placed extension officers in rural areas who played a big role in helping the researcher to select more informative respondents. The researcher also, purposively selected areas with high density of livestock keepers in order to increase the response rate.

Snowball, was used to select the participants. This method is used when it is not easy to identify the respondents or the participants of the study [20]. With Snowball sampling the researcher has to attend one or two respondents in order to identify other respondents. In this study, one livestock keeper was interviewed and thereafter identified other livestock keepers who also helped to identify other participants until the required number of participants is met.

The target respondents for this study were livestock keepers in the southern district part of Botswana. Statistical data of livestock keepers in the study area was extracted from the Central Statistics Office Annual Report of 2014 and shown in Table I. The number of livestock holdings form each subregion was determined by the number of livestock farms. In order to get the sample size for each sub-region, the researcher used a proportional to size sampling method. The sample size was calculated using the formula:

$$
\text { Sample_Size }=\frac{a}{b} * c
$$

Where ' $a$ ' is total number of livestock holdings in a subregion, ' $b$ ' is the total number of livestock farms in the hole region or district, and $\mathrm{c}$ is the total sample size in the region, i.e. ' $c$ ' $=60$.

\section{TABLE I. CATtle Farms Per SUb-Region In SOUthern District}

\begin{tabular}{|l|l|l|}
\hline Sub Region & $\begin{array}{l}\text { No. Of livestock } \\
\text { Holdings }\end{array}$ & $\begin{array}{l}\text { Sample } \\
\text { Size }\end{array}$ \\
\hline Barolong & 1,775 & 8 \\
\hline Ngwaketse North & 1,389 & 6 \\
\hline Ngwaketse South & 1,379 & 7 \\
\hline Ngwaketse Central & 4,487 & 21 \\
\hline Ngwaketse West & 2,172 & 10 \\
\hline Total & $\mathbf{1 1 , 2 0 2}$ & $\mathbf{6 0}$ \\
\hline
\end{tabular}

\section{Data collection techniques and analysis}

In this study, primary and secondary data was collected with the survey method. Primary data was collected using observations, interviews and questionnaires. Secondary data was collected from several different sources such government surveys, media, various publications such as books, journals 
and Internet material. Collected data was systematically recorded and analysed.

\section{RESULTS AND ANALYSIS}

\section{A. Socio-demographic data}

Table II shows the socio-demographic data of 52 respondents from the 60 that was targeted. There are $60 \%$ of male livestock keepers while $40 \%$ are females. Most livestock keepers, 52\% are aged between 30 and 49, while respondents aged above 49 accounted for $31 \%$, and livestock keepers in the age group of 18 to 29 accounted for $17 \%$.

Fifty three percent $(53 \%)$ of livestock keepers have been in this sector for 15 years, and few respondents $(6 \%)$ have been in livestock keeping sector within the past 5 years. Respondents with primary education have the highest percentage $(42 \%)$, followed by those with secondary qualification (27\%), $12 \%$ attended tertiary education, $12 \%$ did adult education and $8 \%$ have no School qualification at all.

TABLE II. SOCIO DEMOGRAPHIC DATA

\begin{tabular}{|l|l|l|l|}
\hline Variable & Measure & frequency & percentage \\
\hline \multirow{3}{*}{ Gender } & Female & 21 & $40 \%$ \\
\cline { 2 - 4 } & Male & 31 & $60 \%$ \\
\hline \multirow{4}{*}{ Fge } & 18 to 29 & 9 & $17 \%$ \\
\cline { 2 - 4 } & 30 to 49 & 27 & $52 \%$ \\
\cline { 2 - 4 } & above 49 & 16 & $31 \%$ \\
\hline \multirow{5}{*}{ Educationing Experience } & 1 to 5 & 3 & $6 \%$ \\
\cline { 2 - 4 } & 6 to 10 & 8 & $15 \%$ \\
\cline { 2 - 4 } & 11 to 15 & 12 & $23 \%$ \\
\cline { 2 - 4 } & above 15 & 29 & $56 \%$ \\
\hline \multirow{5}{*}{} & Adult education & 6 & $12 \%$ \\
\cline { 2 - 4 } & Primary Education & 22 & $42 \%$ \\
\cline { 2 - 4 } & Secondary Education & 14 & $27 \%$ \\
\cline { 2 - 4 } & Tertiary Education & 6 & $12 \%$ \\
\cline { 2 - 4 } & Never in School & 4 & $8 \%$ \\
\hline
\end{tabular}

B. Level of ICT usage by livestock keepers

In one of the research questions the respondents were to declare whether they use ICT for their livestock production activities. Quiet a large number of the respondents $(87 \%)$ indicated that they usedat least one of the ICTs for communicating livestock information while 7 respondents (13 $\%$ ) indicated that they do not use any of the ICTs. The results of this question are shown in Fig 1.

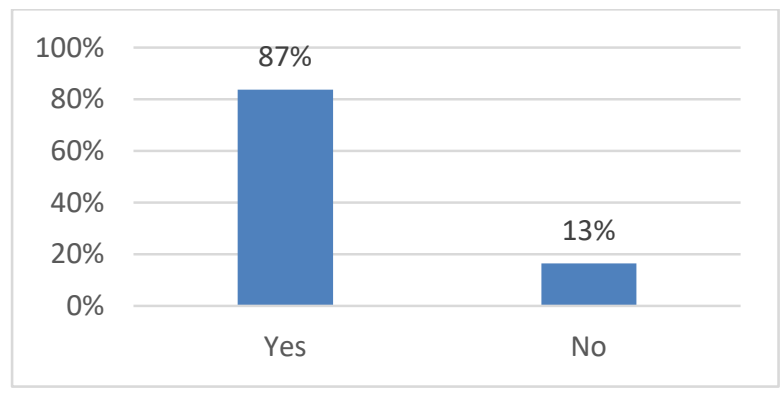

Fig. 1. Level of ICT usage by livestock keepers

The compilation of the survey showed that ICTs are used by many livestock farmers in southern district of Botswana. This is a clear sign that proper use of ICTs can improve livelihoods oflivestock keepers because information shearing between livestock keepers themselves, extension officers and veterinarians may lead to improved livestock keeping practice and quick solving of encountered problems.

Furthermore, the respondents were to indicate the types of ICTs that they use. It appears that most livestock keepers use the radio for accessing information and learning, some use local television, mobile phones, and few livestock keepers have Internet access.

The results displayed in Fig 2. show that mobile phone technology is the most popular ICT used by $94 \%$ the respondents. Livestock keepers also indicated that they have access to the local radio charnel, and more than half of them can afford to buy at least a small FM Radio. Respondents who listen to the radio accounted for $71 \%$, television accounted for $40 \%$. Another type of ICT that was pointed out was the use of Internet by $21 \%$ of the respondents. The results show that the respondents use internet for Facebook (17\%), YouTube (4\%), and email $(8 \%)$.

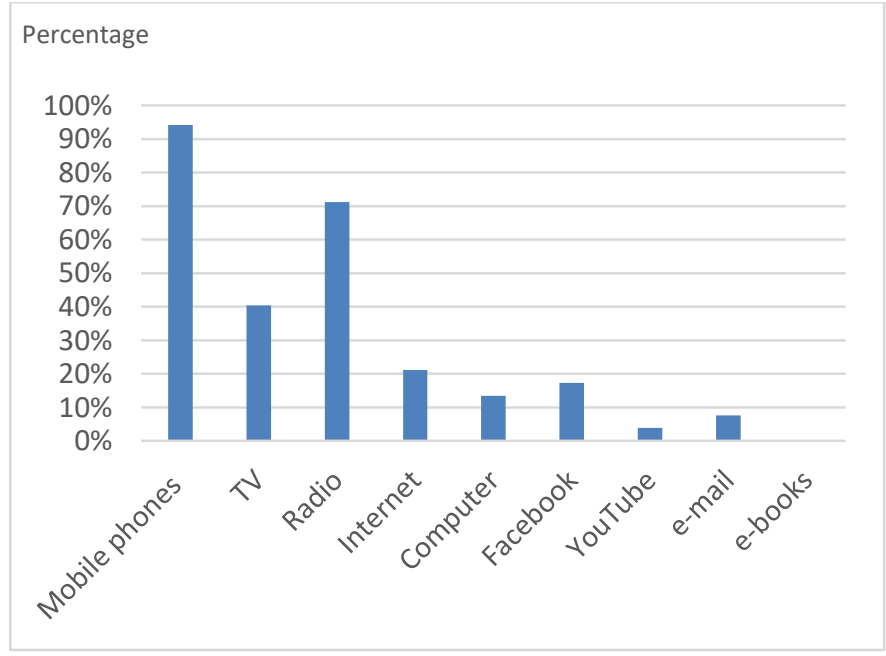

Fig. 2. Typesof ICTs that are used in the study area

\section{Importance of ICTs in livestock information dissemination}

Sometimes the ICTs are not effectively utilized because users don't see the importance of using ICTs in their business. The researcher wanted to understand whether the respondents are aware of the importance of ICT tools to them in accessing livestock information. The findings of this study have shown that a high percentage $(87 \%)$ of respondents agreed that ICT usage is important to them for accessing livestock information. A small percentage of respondents $(13 \%)$ do not see the importance of ICTs.

The reasons given by the respondents were summarized by the researcher as presented in Table IV. Most of the respondents $(35 \%)$ found ICT important in making communication easier and fast. According to my observation and discussion with the respondent all of these respondents use mobile phones and they gave different reasons on how mobile phones make communication easier. Some use mobile phones to communicate with other livestock keepers; others make phone calls to veterinary doctors, and this result in getting help in time. Only $31 \%$ of the respondents indicated that ICT is important since they use it to get technical advice. The 
respondents get the advice through the use of Radio, Television, computers and Internet.

TABLE III. IMPORTANCE OF ICTS IN LIVESTOCK INFORMATION DISSERTATION

\begin{tabular}{|l|l|l|}
\hline Importance & Frequency & Percentage \\
\hline Yes I get technical advise & 16 & $31 \%$ \\
\hline Yes it makes communication easier & 18 & $35 \%$ \\
\hline $\begin{array}{l}\text { Yes But I have no time to use ICT } \\
\text { in livestock keeping }\end{array}$ & 11 & $21 \%$ \\
\hline $\begin{array}{l}\text { I don't see the importance in using } \\
\text { ICT in livestock keeping }\end{array}$ & 7 & $13 \%$ \\
\hline
\end{tabular}

\section{Limitations of using ICTs in the study area}

The outcomes of the question that wanted the farmers to state the factors that hinders them from using ICTs for information dissemination, revealed a number of factors that need to be addressed. Table $\mathrm{V}$ presents the summery of the response from the participants.

TABLE IV. LIMITATIONS OF USING ICTS IN LIVESTOCK KEEPING

\begin{tabular}{|l|l|l|}
\hline Limitation & Frequency & Percentage \\
\hline High communication costs & 44 & $85 \%$ \\
\hline Poor network & 39 & $75 \%$ \\
\hline Long distance to Internet services & 17 & $33 \%$ \\
\hline Lack of computer skills & 36 & $69 \%$ \\
\hline $\begin{array}{l}\text { Unawareness of the programme schedule } \\
\text { on Radio/Television }\end{array}$ & 7 & $13 \%$ \\
\hline Not aware of programs & 11 & $21 \%$ \\
\hline No electricity & 28 & $54 \%$ \\
\hline Lack of confidence in operating ICTs & 22 & $42 \%$ \\
\hline Insufficient regional specific language & 14 & $27 \%$ \\
\hline Negative attitude towards ICTs & 4 & $8 \%$ \\
\hline Lack of training & 41 & $79 \%$ \\
\hline
\end{tabular}

1) High cost of communication

Almost all respondents mentioned that the cost of communication with mobile phones is high. The mobile phone call rates are said to be high especially during business hours. The respondents also complained about the high cost of internet subscription, stating that this high communication charges are affecting use of mobile phones. The respondents mentioned that the Government does not give allowances for mobile communication to the extension officers. They use their personal mobile phones at their own expenses and this hampers the use of mobile phones in information dissemination since extension officers who have knowledge in livestock farming cannot communicate with all livestock keepers.

\section{2) Poor mobile communication Network signal}

Another limiting factor that was mentioned by $75 \%$ of the respondents was poor mobile communication Network signal. In addition, the researcher observed that in some areas there is no Network signal at all. Farmers stated that sometimes they have to travel to nearby areas where there is a communication Network In order for them to use their mobile phones. This increase the communication cost and time consuming.

3) Unawareness of radio and television programmes and their schedules

Some respondents, $13 \%$ are not aware of the time programs were broadcasted. This is a limitation because respondents cannot listen or follow this informative program. Even the worst case, some livestock keepers $11 \%$ do not know that there exist educative livestock programs on radio and television. These are the livestock keepers who declared that they do not have radio nor television set at their homes due to different reasons such as: lack of money to buy; poor or no radio and television signal in their area; lack of electricity and others.

\section{4) Lack of electricity}

This study reports that $54 \%$ of the respondents have no electric power connection in their homes. The researcher observed that power connection is not yet done in rural areas that are distanced from the main tarred roads. Power connection is done in livestock farms and homes alongside the main roads. The respondents said that this situation is depriving them the chance to watch television and listening to the radio in order to benefit from these livestock programs. Some livestock keepers who have electricity complained about the national crisis of power rationing.

\section{DISCUSSION OF FINDINGS AND RECOMMENDATIONS ON IMPROVEMENT OF ICT USAGE}

This study is focused on finding out the level of ICT awareness and usage by livestock farmers in Southern District part of Botswana. The researcher want to understand the types of ICTs that are used, and if livestock keepers are aware of the importance of ICT usage in their livestock farming activities. Data was collected from 122 livestock farmers in the study area. A quick observation as well as secondary evidence from Central Statistics Office Annual report (2014) shows that goats, cattle, sheep and poultry are the major livestock kept by livestock keepers in the study area.

During data collection, the researcher had to first explain to most of the participants why they need to participate in the study and the question had to be translated and explained to them in their local language, Setswana. This was an exceptional to a few large farms at Borolong area. The few large farms had more staff; some had offices unlike the small scale. Some of the large farms used diesel generators for electricity.

The percentage of male livestock keepers (66\%) who participated is higher than that of female livestock keepers (34\%). Most farmers are aged between 30 and 49 years old. The study indicates the participation of young persons. Remarkably more than $33 \%$ reported that they have secondary and tertiary education.

Almost all the participants can afford and are using mobile phones. Also about six out of ten have access and are using radio and television. From the literature review of this study, a number of studies that have been conducted in some African countries had this pattern of response.

It turns out that mobile phone technology is currently the most popular ICT of the present society. This is because of its portability, low cost, simple to use together with its capabilities of multitasking. Livestock application designers and developers are therefore, advised to come up with systems that operates on commonly available technology devices, i.e. mobile devices for now. Also the systems need to be presented 
in local languages in order to include the largest possible number of end users.

Apart from mobile phones, it is also observed that radio is listened by a large percentage of livestock keepers. This is because radios have unique qualities, and most mobile phones have radios embedded making the radio to be one of the popularly used ICT. Radios can operate on batteries, are affordable, and most mobile phone have FM radio embedded. However, to my observation and discussion with the respondents, there is a lack of awareness that their mobile phones have radios embedded. One of the short falls of the radio is that it is a one way communication system unlike mobile phones. For this radio presenters need to be clear and explain in details to ensure that listeners have no questions in the information that they receive.

In regardless of the good qualities of the radio, the results of this study showed that there are livestock farmers who do not know about the existence of radio nor livestock programs. The radio and television programs' details need to be advertised through other mediums such as newspapers, and during gatherings such as 'Kgotla meetings'. This can increase the number of livestock keepers who follow or listen to them and hence benefiting from them.

There are livestock keepers who are not able to follow the television and radio livestock programs because of unfavorable time schedule of the programs. Livestock keepers indicated that programs are scheduled on day time when livestock keepers are out doing livestock rearing activities. As a result, it is advisable to review and improve these programme schedules in order to attract more listeners. The researcher suggests that the programmes should be broadcasted at night around 08:00 pm when most livestock keepers are available to watch and listen to this program. Also, livestock programs need to be made more interactive by inviting the listeners to make phone calls to the radio and television to seek for clarification and ask question. This can be possible since a lot of livestock keepers since almost all of them have mobile phones.

\section{CONCLUSION}

This study has discovered that use of ICTs by livestock keepers for the purpose of improving their livestock production activities in the southern district of Botswana is not satisfying. Radio, mobile phones, and television are the identified types of ICT that are used most frequently by livestock keepers, though they are not used at satisfactory level for livestock production. ICT usage and access is limited by lack of computer skills, high cost of computers and Internet access, unawareness of livestock programs on radio and television, lack of ICT infrastructure in rural areas, and others. If these challenges can be resolved, there can be a significant improvement in livestock production especially in remote rural areas where livestock keeping is highly practiced.

\section{REFERENCES}

[1] CSO, "Annual Agricultural Report," Central Statistics Office, Gaborone, 2014.

[2] D. B. Gosalamang, J. J. Hlongwane and M. Masuku, "Supply Response of Beef Farmers in Botswana: A Nerlovian partial adjustments Model approach," African Journal of Agricultural Research, vol. 7, no. 31, pp. 4383-4389, 2012

[3] B. Malema, "Botswana's formal economic structure as a possible source of poverty: Are there any policies out of this economic impasse?", PULA: Botswana Journal of African Studies, vol. 26, no. 46, 2012.

[4] G. Honde, "Botswana," AfDB, OECD, UNDP, 2015.

[5] E. E. Williams and I. S. Agbo, "Evaluation of the Use of ICT in Agricultural Technology Delivery to farmers in Ebonyi State, Nigeria," Journal of Information Engineering and Applications, vol. 3, no. 10, 2013.

[6] C. Angello, "Exploring the Use of ICT in Learning and Disseminating Livestock Husbandry knowledge to urban and per-urban communities in Tanzania," International Journal of Education and Development Using Information and communication Technology(IJEDICT), vol. 11, no. 2, pp. 5-22, 2015.

[7] N. Williams and O. Soremi, "ICT Use in Livestock Innovation Chain in Ibadan City in Nigeria," Advances in Life Science and Technology, vol. 32, pp. 30-43, 2015.

[8] B. Rudolph, "Cattle Traceability-A Threat to Sustainable Suppy of Beef to EU: A Botswana Meat Commission," European Centre for Research Training and Development UK, vol. 1, pp. 1-9, 2013.

[9] M. Meyn, "The end of Botswana beef exports to European Union," London SE 17 JD: Overseas Development Institute, 111 Westminister Bridge Road, 2007.

[10] B. A. Temba, F. K. Kajuna, G. S. Pango and R. Benard, "Accessibility and use of information and communication tools among farmers for improving chicken production in Morogo municipality, Tanzania," Livestock Research for rural development, vol. 28, no. 11, 2016.

[11] W. P. Mtenga and A. C. Msungu, "Using Information and Communication Technologies for enhancing the accessibility of agricultural information for improved agricultural production in Tanzania.," The Electronic Journal on Information Systems in Developing Countries, vol. 56, no. 1, pp. 1-14, 2013.

[12] T. Mogotlhwane, F. Khosrowshahi and J. Underwood, "ICT Challenges in Developing Countries: Botswana's Perspective," International Journal of Computer and Information Technology, vol. 2, no. 6, pp. 1054-1058, November 2013.

[13] BOCRA, "BOCRA," 15 November 2016. [Online]. Available: http://www.bocra.org.bw/telecoms-statistics. [Accessed 17 November 2015].

[14] S. Arshad, A. Saghir and M. Ashfaq , "Gender and Decision Making Process in Livestock Management," Sarhad J. Agric, vol. 26, no. 4, pp. 132-135, 2010.

[15] B. E. Mooketsi, "Optimization of Livestock Identification and Trace-back System LITS Database to Meet Local Needs: Case Study of Botswana," The Journal of Community Informatics, vol. 9, no. 4, 2013.

[16] T. Mogotlhwane , F. Khosrowshahi and J. Underwood, "Information technology productivity paradox," in 6th International Postgraduate Research Conference, Netherlands, 2006.

[17] Case study: Institution-Based Information System, Egypt, The Experience of VERCON in Egypt, 2016.

[18] Marketing: Linking local learners, 2016.

[19] J. W. Creswell, Research Design: Qualitative, Quantitative and Mixed Methods, Second ed., SAGE Publications, 2003.

[20] M. Saunders, P. Lewis and D. Thornhill, Research Methods for Business Students, London: Pearson Education Limited, 2007. 